\title{
The relation between body image satisfaction, self-esteem and the academic behavior among the first and fourth year students in the Faculty of Nursing Tanta University
}

\author{
Zebeda Abd El Gawad Elsherif,, Ayat Saif Elyzal Abdelraof \\ Mental Health and Psychiatric Nursing, Faculty of Nursing, Tanta University, Tanta, Egypt
}

Received: October 5, 2017

Accepted: January 25, 2018

Online Published: January 29, 2018

DOI: $10.5430 /$ cns.v6n3p28

URL: https://doi.org/10.5430/cns.v6n3p28

\begin{abstract}
Background: Body image is interrelated to a person's self-esteem. Misperception about one's body can be the cause of disturbed self-esteem, and this result in low academic achievement. The objective of this study is to explore the relation between body image satisfaction, self-esteem and the academic behavior among the first and fourth year students in faculty of nursing.

Methods: A comparative description design was utilized for this study. Three tools used for this study: Tool 1, Part 1: Sociodemographic and general characteristics of studied nursing students, Part 2: The Body Shape Questionnaire modified version 14 (BSQ) scale. Tool 2: The Rosenberg Self-Esteem Scale (RSE). Tool 3: the Measurement of Academic Behavior.

Results: The results of this study showed that there was a significant negative correlation between body image dissatisfaction and self-esteem in the first year students as $r=0.167$ and $p=.018$, also in the fourth year students as $r=0.285$ and $p \leq .001$. There was a significant positive correlation between self-esteem and academic behavior in the first year students as $r=-0.253$ and $p \leq$ .001 . While in the fourth year students there was a significant positive correlation between their self-esteem and their academic behavior at $r=0.235$ and $p \leq .001$.

Conclusions: The results concluded that the students had a large percent of dissatisfaction with their body image and low self-esteem level, also they had low level of academic behavior. This study recommended that future research need positive psychiatric management which relates cognitive framing with applied behavior to elevate body image satisfaction and self-esteem and also to elevate physical activity.
\end{abstract}

Key Words: Body image dissatisfaction, Students, Self-esteem, Academic behavior

\section{INTRODUCTION}

Adolescence is a critical stage in life; as a result it is a transitional stage in the middle of adolescence and maturity, adolescents begin looking for flexibility and freedom. This phase is characterized by various progressions in psychological, physiological and social responses. So the adolescents face distinctive difficulties in managing these rapid progressions which influence their satisfaction about their bodies. ${ }^{[1]}$

Some of the challenges related to self-construction of the adolescent are physical rather than emotional changes that show the movement from being child to adult. With physical appearance puberty and self-esteem become significant to

\footnotetext{
*Correspondence: Zebeda Abd El Gawad Elsherif; Email: z.alsherif@gmail.com; Address: Mental Health and Psychiatric Nursing, Faculty of Nursing, Tanta University, Tanta, Egypt.
} 
the global self-image of an adolescent. Those physiological and emotional changes can affect important consequences on self-esteem as whole and developing academic behaviors in particular, which is important for academic achievement for adolescents. ${ }^{[2]}$

Adolescents' body assumes an important role in forming their self-image and thoughts of his/her physical manifestation in the eyes of others. Self-image is formed as a result of various variables for example, such that social upbringing, community, culture, media, family and friends. ${ }^{[3]}$ Consequently physiological and body changes of adolescents make adolescents more concentrated upon their body image. This image may be influenced by body changes and the opinions of others around body shape, these changes might have a negative impact upon those adolescents' behavior, mental wellbeing and self-esteem. ${ }^{[4]}$

The degree of body image has critical impact on their functions in all aspects of life especially in growing times. Several outcomes connected with one's level of body satisfaction such as academic absenteeism, feeling for muscularity, selfconfidence and mental health, achievements in life, eating behavior, and addictions. ${ }^{[5]}$

Self-image issues become important in adolescence time in which the identity building and strong sense of self are major developmental task. So, physical appearance and self-image are interrelated and the self-image is that strongest predictor for self-esteem between male and female adolescents. Body appearance provides several functions in male and females adolescents with importance for self-confidence. ${ }^{[6]}$ Self-esteem is a term utilized within psychology to reflect a person's generally assessment of his or her own worth. Sense of belonging, feeling of constantly acknowledged and an inclination of constantly a skilful individual would be vital parts of self-esteem. An individual has a low self-esteem shows self-rejection, poor self-respect, and disagreeable selfpicture. $^{[7]}$

The self-image theory states that satisfaction with body picture has critical impact on global self-esteem. Low selfesteem predisposes to eating disorders and body image dissatisfaction. The individuals who had high body image dissatisfaction showed inferior self-esteem. ${ }^{[8]}$ Various studies show a positive relation between self-esteem and academic achievement. It showed that the relationship between selfesteem and academic achievement is bidirectional. In other words, self-esteem and academic achievement reciprocally affect one another. ${ }^{[9]}$

Academic accomplishment is one of the important other aims of education as well. It is a critical factor in life as it is groundwork to ambition and advancement. ${ }^{[10]}$ Studies have

Published by Sciedu Press additionally demonstrated that academic accomplishment may be additionally specifically affected by level of selfesteem. Self-esteem is the self-worth, the global evaluation of one's personality. It is related to many life components. ${ }^{[11]}$

Adolescents who are refused by their companions make academic problems. Better academic achievements and extracurricular activities can help in prevention of negative behaviors, better adolescents' performances, future well-being and success. $^{[12]}$

Several studies hint at that self-esteem impacts academic behavior. These researches propose that low self-esteem impair academic accomplishment as a result of feelings of worthlessness can be depressing and depression inhibits academic achievement. In addition dread of disappointment might cause students with low self-esteem to hold back, whereas students with high self-esteem may be more likely to take a risk. Regardless, the research obviously demonstrates that self-image influences self-esteem and that self-esteem influences academic accomplishment. ${ }^{[13,14]}$

There is a need to review the nursing curriculum and evaluate what impacts body image satisfaction and self-esteem of nursing students. Hence it is important to assess the relation between body image satisfaction, self-esteem and the academic behavior among the first and fourth year students in the faculty of nursing. So, preventative strategies are important to improve adolescent's body image satisfaction and self-esteem.

\subsection{The study aim}

To explore the relation between body image satisfaction, selfesteem and the academic behavior among the first and fourth year students in Faculty of Nursing Tanta University.

\subsection{Research questions}

- Is there a relation between the first and fourth year students in their body image satisfaction and academic behavior in the Faculty of Nursing Tanta University?

- Is there a relation between the first and fourth year students in their self-esteem and academic behavior in the Faculty of Nursing Tanta University?

\section{SUBJECTS AND METHOD}

\subsection{Research design}

The present study followed a comparative description research design.

\subsection{Setting}

The study was carried out at Faculty of Nursing in Tanta University, first and fourth graduate nursing male and female students. 


\subsection{Subjects}

The study subjects (400) selected randomly from first and fourth graduate nursing students according to the EpiInfo statistic program, 200 student form the first grade and 200 students from the fourth grade invited to participate in the study.

\subsection{Tools}

The data of this study was collected using the following tools:

\subsection{1 $\operatorname{Tool}(1)$}

Tool (1): consisted of 2 parts:

Part (1): Socio-demographic and general characteristics of studied nursing students include; e.g. (age, sex, residence, marital status, having children, income, having sibling, and academic study year).

Part (2): The Body Shape Questionnaire modified version 14 (BSQ) scale developed by Cooper et al. ${ }^{[15]}$ It is composed of 14 items to measure issues related body image dissatisfaction It was relying on a six-point Likert scale ranging from never ( 1 point) to always ( 6 points) and was completed in about five to ten minutes.

Scoring: For body image satisfaction the sum total of 14 items will be derived. The maximum score will be 84 points means concerns about body image dissatisfaction and minimum score will be 14 points means no concerns about body image dissatisfaction. Higher scores will indicate higher levels of body image dissatisfaction and lower scores will indicate higher levels of body image satisfactions.

- Higher levels: 43-84 means concerns about body image dissatisfaction

- Lower levels: 14-42 means no concerns about body image dissatisfaction

\subsubsection{Tool (2)}

Tool (2): The Rosenberg Self-Esteem Scale (RSE). ${ }^{[16]}$ Self-esteem was assessed by using agreements with selfevaluative statements such as "On the whole I am satisfied with myself." It was a 10-items scale with items answered on a four points Likert scale from strongly agrees (3 points) to strongly disagree ( 0 point).

Scoring: For self-esteem assessment, the sum of scores for the 10 items. The maximum score was 30 points and minimum score was 0 point. Higher scores indicate the higher self-esteem.

- Low self-esteem $\leq 15$

- High self-esteem 16-30

\subsubsection{Tool (3)}

Tool (3): The Measurement of Academic Behavior developed by Gupta C. ${ }^{[17]}$ Questions were used to assess frequencies (i.e. how often) of faculty students' to countable behaviors related to their academics. The questions of this scale were as, "I like hard work because I see it as a challenge" and "I finish an assignment by the deadline", (MAB) scale was consisting of 20 items that were measured by using a Likert scale that ranged from "never" (1 point) to "always" (5 points).

Scoring: For academic behavior, the sums of the 20 items were calculated. Higher scores indicated higher levels of academic behaviors thus lead to higher levels of academic achievements.

- Low level of academic behavior: $\leq 50$

- High level of academic behavior: 51-100

\subsection{Methods}

Official permission to conduct the study was obtained from faculty of nursing at Tanta University.

Throughout the study process the following ethical points were considered:

- Participation in the study was voluntary and informed consent was obtained from the studied nursing students to participate in the study.

- Explanation the purpose of the study and emphasizing the right to withdraw at any point during the study.

- Assuring students about their privacy and confidentiality of the obtained data.

- Orienting the participants about date, time and place of data collection.

- Orienting the participants that collected data will be used only for the purpose of scientific research.

Content validity of the tool was performed by five experts in the field of nursing. The expert panels were asked to evaluate the developing questions after translation according to readability, language appropriateness to avoid biases, and ease of understanding items.

Before embarking in the actual study, a pilot study was carried out on 40 students; 20 from first grade and 20 from fourth grade. After taking a consent, to ascertain the clarity and applicability of the study tools and to identify obstacles that may be faced during data collection, these students were excluded from the study subjects. After its implementation and according to its results a necessary modification was done.

Reliability of the tool of BSQ was tested by using Conbach's alpha to be $0.96-0.97$ by Cooper et al.; ${ }^{[15]}$ For the Rosenberg 
RSE was 0.84 by Rosenberg M; ${ }^{[16]}$ For the Measurement of Academic Behavior (MAB) was 0.82 by Gupta C. ${ }^{[17]}$

\subsubsection{Actual study}

A written consent was obtained from each selected student according to their willingness for participation in the study after explaining the aim of the study, establishing rapport and trusting relationship with the studied students.

The form of the study tools was distributed and explained to nursing students $(\mathrm{n}=400)$ after finishing their lectures or lab and they were reassured that all information will be confidential and used only for the purpose of the study and they were individually interviewed for keeping their privacy.

Tools of the study were implemented by the researcher using the interview questionnaire sheet to determine the body image dissatisfaction level, self-esteem level, and their academic behavior.

Each interview was implemented on an individual basis and lasted for about 20-40 minutes according to students's attention and willing to cooperate or talk with the researcher.

Data were collected over a period of about 3 months starting from October 2016 and ending in December 2016.

\subsubsection{Statistical analysis}

The collected data were organized, tabulated and statistically analyzed using SPSS software statistical computer package version 20. For quantitative data, the range, mean and standard deviation were calculated. For comparison between means, Chi-square test was used. Correlation between variables was evaluated using Pearson's correlation coefficient $r$. A significance was adopted at $p<.05$ for interpretation of results of tests of significance.

\section{Results}

Table 1 presents the Socio-demographic characteristics of studied samples. The results revealed that the first year students $(99 \%)$ had less than 20 years old with a mean of age 18.3 , while the fourth year students $(100 \%)$ had more than 20 years old with a mean of age 21.8. Concerning students' sex $(66 \%)$ of them were female in the first year students, while the majority of them $(71 \%)$ in the fourth year were female. As regards their residence $68 \%$ of the first year students live in rural while $(58 \%)$ of the fourth year students were live in rural.

Regarding marital status most of first year students (97\%) were single and also $81 \%$ of the fourth year. Concerning their family income most of the first year students $(86 \%)$ their family income were enough, while $83 \%$ of the fourth year students their family income were enough. Regarding number of family member, most of the first year and fourth year students their family had members range from 1 to 3 members only.

Table 1. Socio-demographic characteristics of studied samples

\begin{tabular}{|c|c|c|c|c|}
\hline & \multicolumn{2}{|c|}{$\begin{array}{l}\text { First year } \\
(\mathrm{N}=\mathbf{2 0 0})\end{array}$} & \multicolumn{2}{|c|}{$\begin{array}{l}\text { Fourth year } \\
(N=200)\end{array}$} \\
\hline & $\mathbf{N}$ & $\%$ & $\mathbf{N}$ & $\%$ \\
\hline \multicolumn{5}{|l|}{ Age } \\
\hline$\bullet<20$ & 198 & 99.0 & 0 & 0 \\
\hline - 20 and more & 2 & 1.0 & 200 & 100.0 \\
\hline Mean $\pm S D$ & \multicolumn{2}{|c|}{$18.3 \pm 0.49$} & \multicolumn{2}{|c|}{$21.8 \pm 1.09$} \\
\hline \multicolumn{5}{|l|}{ Sex } \\
\hline - Male & 68 & 34.0 & 58 & 29.0 \\
\hline - Female & 132 & 66.0 & 142 & 71.0 \\
\hline \multicolumn{5}{|l|}{ Residence } \\
\hline - Urban & 64 & 32.0 & 83 & 41.5 \\
\hline - Rural & 136 & 68.0 & 117 & 58.5 \\
\hline \multicolumn{5}{|l|}{ Marital status } \\
\hline - Single & 194 & 97.0 & 162 & 81.0 \\
\hline - Married & 6 & 3.0 & 38 & 19.0 \\
\hline \multicolumn{5}{|l|}{ With children } \\
\hline - Yes & 5 & 2.5 & 21 & 10.5 \\
\hline - No & 195 & 97.5 & 179 & 89.5 \\
\hline \multicolumn{5}{|l|}{ Family income } \\
\hline - Enough & 172 & 86.0 & 166 & 83.0 \\
\hline - Not enough & 28 & 14.0 & 34 & 17.0 \\
\hline \multicolumn{5}{|c|}{ Number of family members } \\
\hline - $1-3$ & 169 & 84.5 & 141 & 70.5 \\
\hline - 4-6 & 31 & 15.5 & 59 & 29.5 \\
\hline
\end{tabular}

As shown in Table 2 the results revealed the comparison between first and fourth year students' total score of body image dissatisfaction, self-esteem, \& academic behavior, where there was a significant statistical relationship between the first year and fourth year students in their body image dissatisfaction at $\chi^{2}=5.005, p=.025$. As regards selfesteem also there was a significant statistical relationship between the first and fourth year students in their self-esteem at $\chi^{2}=10.526, p \leq .001$. Concerning academic behavior there was a significant statistical relationship between the first year and fourth year students in their academic behavior at $\chi^{2}=$ $21.594, p \leq .001$.

Table 3 presents the correlation between first and fourth year students in body image total score, self-esteem total score, and academic behavior total score. the results showed that there was a significant negative correlation between body image dissatisfaction and self-esteem in the first year students as $r=0.167$ and $p=.018$, also in the fourth year students at $r=0.285$ and $p \leq .001$.

There was a significant positive correlation between selfesteem and academic behavior in the first year students $r=-0.253$ and $p \leq .001$, while in the fourth year students 
there was a significant positive correlation between their self- in the first year students at $r=-0.032$ and $p=.652$, also in esteem and their academic behavior at $r=0.235$ and $p \leq$ .001. There was a negative correlation but not significant among body image dissatisfaction and academic behavior the fourth year students there was a significant negative correlation between their body image dissatisfaction and their academic behavior at $r=-0.369$ and $p \leq .001$.

Table 2. Comparison between first and fourth year students' total score of body image dissatisfaction, self-esteem, \& academic behavior

\begin{tabular}{|c|c|c|c|c|c|c|}
\hline & \multicolumn{2}{|c|}{ First year $(\mathrm{N}=200)$} & \multicolumn{2}{|c|}{ Fourth year $(\mathrm{N}=200)$} & \multirow{2}{*}{$\chi^{2}$} & \multirow{2}{*}{$p$-value } \\
\hline & $\mathbf{N}$ & $\%$ & $\mathbf{N}$ & $\%$ & & \\
\hline \multicolumn{7}{|c|}{ Body image dissatisfaction } \\
\hline - Low 14-42 & 15 & 7.5 & 29 & 14.5 & \multirow{2}{*}{5.005} & \multirow{2}{*}{$.025^{*}$} \\
\hline - High 43-84 & 185 & 92.5 & 171 & 85.5 & & \\
\hline Mean $\pm S D$ & \multicolumn{2}{|c|}{$27.14 \pm 13.08$} & \multicolumn{2}{|c|}{$31.09 \pm 12.80$} & & \\
\hline \multicolumn{7}{|l|}{ Self-esteem } \\
\hline - Low $\leq 15$ & 145 & 72.5 & 114 & 57 & \multirow{2}{*}{10.526} & \multirow{2}{*}{$<.001^{*}$} \\
\hline - High $16-30$ & 55 & 27.5 & 86 & 43 & & \\
\hline Mean $\pm S D$ & \multicolumn{2}{|c|}{$18.45 \pm 4.51$} & \multicolumn{2}{|c|}{$18.45 \pm 3.58$} & & \\
\hline \multicolumn{7}{|c|}{ Academic behavior } \\
\hline - Low 25-50 & 179 & 89.5 & 142 & 71 & & \\
\hline - High 51-100 & 21 & 10.5 & 58 & 29 & 21.594 & $<.001^{*}$ \\
\hline Mean $\pm S D$ & \multicolumn{2}{|c|}{$67.35 \pm 9.34$} & \multicolumn{2}{|c|}{$71.29 \pm 12.13$} & & \\
\hline
\end{tabular}

Note. ${ }^{*}$ Significant at level $p<.05$

Table 3. Correlation between first and fourth year students in body image total score, self-esteem total score, and academic behavior total score

\begin{tabular}{|c|c|c|c|c|}
\hline & \multicolumn{2}{|c|}{ Self-esteem } & \multicolumn{2}{|c|}{ Body image dissatisfaction } \\
\hline & $\mathbf{R}$ & $p$-value & $\mathbf{R}$ & $p$-value \\
\hline \multicolumn{5}{|l|}{ First year } \\
\hline - Body image dissatisfaction & -0.167 & $.018^{*}$ & & \\
\hline - Academic behavior & 0.253 & $<.001^{*}$ & -0.032 & .652 \\
\hline \multicolumn{5}{|l|}{ Fourth year } \\
\hline - Body image dissatisfaction & -0.285 & $<.001^{*}$ & & \\
\hline - Academic behavior & 0.235 & $<.001^{*}$ & -0.369 & $<.001^{*}$ \\
\hline
\end{tabular}

Note. ${ }^{*}$ Correlation is significant at $p<.05$

Table 4 presents the relation between students' sociodemographic characteristics and their body image dissatisfaction total score. The results revealed that there was a statistical significant relation between first year students' sex and their body image dissatisfaction at $\chi^{2}=5.399$ and $p=.020$, also in the fourth year students there was a statistical significant relation between their sex and their body image dissatisfaction at $\chi^{2}=3.809$, and $p=.048$.

There was a statistical significant relation between first year students' residence and their body image dissatisfaction at $\chi^{2}=4.783$, and $p=.029$, while there was no statistical significant relation between fourth year students' residence and their body image dissatisfaction at $\chi^{2}=0.155$, and $p=.694$.

Concerning marital status there was a statistical significant relation between fourth year students' marital status and their body image dissatisfaction at $\chi^{2}=5.283$, and $p=.022$, while there was no statistical significant relation between first year students' marital status and their body image dissatisfaction at $\chi^{2}=0.502$, and $p=.479$

Table 5 shows the relation between students' sociodemographic characteristics and their self-esteem total score. This table illustrate that there was a statistical significant relation between first year students' sex and their self-esteem at $\chi^{2}=4.436$, and $p=.035$, while there was no statistical 
significant relation between fourth year students' sex and while there was no statistical significant relation between their self-esteem at $\chi^{2}=0.111$, and $p=.739$. Also there was fourth year students' residence and their self-esteem at $\chi^{2}=$ a statistical significant relation between first year students' 0.608 , and $p=.436$.

residence and their self-esteem at $\chi^{2}=5.02$, and $p=.025$,

Table 4. Relation between students' socio-demographic characteristics and their body image dissatisfaction total score

\begin{tabular}{|c|c|c|c|c|c|c|c|c|c|c|c|c|}
\hline & \multicolumn{12}{|c|}{ Body image dissatisfaction } \\
\hline & \multicolumn{6}{|c|}{ First year } & \multicolumn{6}{|c|}{ Fourth year } \\
\hline & \multicolumn{2}{|c|}{ Low } & \multicolumn{2}{|c|}{ High } & \multirow{2}{*}{$\chi^{2}$} & \multirow{2}{*}{$p$-value } & \multicolumn{2}{|c|}{ Low } & \multicolumn{2}{|c|}{ High } & \multirow{2}{*}{$\chi^{2}$} & \multirow{2}{*}{$p$-value } \\
\hline & $\mathbf{N}$ & $\%$ & $\mathbf{N}$ & $\%$ & & & $\mathbf{N}$ & $\%$ & $\mathbf{N}$ & $\%$ & & \\
\hline \multicolumn{13}{|l|}{ Age } \\
\hline - 20 & 0 & 0.0 & 183 & 92.4 & \multirow{2}{*}{0.164} & \multirow{2}{*}{.686} & & & & & & \\
\hline - 20 or more & 15 & 7.6 & 2 & 100.0 & & & & & & & & \\
\hline \multicolumn{13}{|l|}{ Sex } \\
\hline - Male & 1 & 1.5 & 67 & 98.5 & \multirow{2}{*}{5.399} & \multirow{2}{*}{$.020^{*}$} & 4 & 6.9 & 54 & 93.1 & \multirow{2}{*}{3.809} & \multirow{2}{*}{$.048^{*}$} \\
\hline - Female & 14 & 10.6 & 118 & 89.4 & & & 25 & 17.6 & 117 & 82.4 & & \\
\hline \multicolumn{13}{|l|}{ Residence } \\
\hline - Urban & 1 & 1,6 & 63 & 98.4 & \multirow{2}{*}{4.783} & \multirow{2}{*}{$.029^{*}$} & 13 & 15.7 & 70 & 84.3 & \multirow{2}{*}{0.155} & \multirow{2}{*}{.694} \\
\hline - Rural & 14 & 10.3 & 122 & 89.7 & & & 16 & 13.7 & 101 & 86.3 & & \\
\hline \multicolumn{13}{|l|}{ Marital status } \\
\hline - Single & 15 & 7.7 & 179 & 92.3 & \multirow{2}{*}{0.502} & \multirow{2}{*}{.479} & 19 & 11.7 & 143 & 88.3 & \multirow{2}{*}{5.283} & \multirow{2}{*}{$.022 *$} \\
\hline - Married & 0 & 0.0 & 6 & 100.0 & & & 10 & 26.3 & 28 & 73.7 & & \\
\hline \multicolumn{13}{|c|}{ Student with children } \\
\hline - Yes & 0 & 0.0 & 5 & 100.0 & 0416 & 510 & 2 & 13.3 & 13 & 86.7 & 0018 & 804 \\
\hline - No & 15 & 7.7 & 180 & 92.3 & 0.416 & .519 & 27 & 14.6 & 158 & 85.4 & 0.018 & .894 \\
\hline Family income & & & & & & & & & & & & \\
\hline - Enough & 14 & 8.1 & 158 & 91.9 & 0724 & 305 & 22 & 13.3 & 144 & 86.7 & 1225 & 268 \\
\hline - Not enough & 1 & 3.6 & 27 & 96.4 & 0.124 & .395 & 7 & 20.6 & 27 & 79.4 & 1.225 & .268 \\
\hline Number of family & & & & & & & & & & & & \\
\hline - $(1-3)$ & 13 & 7.7 & 156 & 92.3 & 0058 & 800 & 19 & 13.5 & 122 & 86.5 & 0405 & 525 \\
\hline - $(4-6)$ & 2 & 6.5 & 29 & 93.5 & 0.058 & .809 & 10 & 16.9 & 49 & 83.1 & 0.405 & .525 \\
\hline
\end{tabular}

Note. ${ }^{*}$ Significant at level $p<.05$

Table 5. Relation between students' socio-demographic characteristics and their self-esteem total score

\begin{tabular}{|c|c|c|c|c|c|c|c|c|c|c|c|c|}
\hline & \multicolumn{12}{|c|}{ Self-esteem } \\
\hline & \multicolumn{6}{|c|}{ First year } & \multicolumn{6}{|c|}{ Fourth year } \\
\hline & \multicolumn{2}{|c|}{ Low } & \multicolumn{2}{|c|}{ High } & \multirow{2}{*}{$\chi^{2}$} & \multirow{2}{*}{$p$-value } & \multicolumn{2}{|c|}{ Low } & \multicolumn{2}{|c|}{ High } & \multirow{2}{*}{$\chi^{2}$} & \multirow{2}{*}{$p$-value } \\
\hline & $\mathbf{N}$ & $\%$ & $\mathbf{N}$ & $\%$ & & & $\mathbf{N}$ & $\%$ & $\mathbf{N}$ & $\%$ & & \\
\hline \multicolumn{13}{|l|}{ Age } \\
\hline - 20 & 143 & 72.2 & 55 & 27.8 & \multirow{2}{*}{0.766} & \multirow{2}{*}{.381} & & & & & & \\
\hline - 20 or more & 2 & 100.0 & 0 & 0.0 & & & & & & & & \\
\hline \multicolumn{13}{|l|}{ Sex } \\
\hline - Male & 43 & 63.2 & 25 & 36.8 & \multirow{2}{*}{4.436} & \multirow{2}{*}{$.035^{*}$} & 32 & 55.2 & 26 & 44.8 & \multirow{2}{*}{0.111} & \multirow{2}{*}{.739} \\
\hline - Female & 102 & 77.3 & 30 & 22.7 & & & 82 & 57.7 & 60 & 42.3 & & \\
\hline \multicolumn{13}{|l|}{ Residence } \\
\hline - Urban & 53 & 82.8 & 11 & 17.2 & \multirow{2}{*}{5.02} & \multirow{2}{*}{$.025^{*}$} & 50 & 60.2 & 33 & 39.8 & \multirow{2}{*}{0.608} & \multirow{2}{*}{.436} \\
\hline - Rural & 92 & 67.6 & 44 & 32.4 & & & 64 & 54.7 & 53 & 45.3 & & \\
\hline \multicolumn{13}{|l|}{ Marital status } \\
\hline - Single & 140 & 72.2 & 54 & 27.8 & \multirow{2}{*}{0.364} & \multirow{2}{*}{.546} & 92 & 56.8 & 70 & 43.2 & \multirow{2}{*}{0.015} & \multirow{2}{*}{.901} \\
\hline - Married & 5 & 83.3 & 1 & 16.7 & & & 22 & 57.9 & 16 & 42.1 & & \\
\hline \multicolumn{13}{|c|}{ Student with children } \\
\hline - Yes & 4 & 80.0 & 1 & 20.0 & & & 9 & 60.0 & 6 & 40.0 & & \\
\hline - No & 141 & 72.3 & 54 & 27.7 & 0.145 & .704 & 105 & 56.8 & 80 & 43.2 & 0.060 & .807 \\
\hline Family income & & & & & & & & & & & & \\
\hline - Enough & 125 & 72.7 & 47 & 27.3 & & & 100 & 60.2 & 66 & 39.8 & & \\
\hline - Not enough & 20 & 71.4 & 8 & 28.6 & 0.019 & .891 & 20 & 58.8 & 14 & 41.2 & 4.185 & $.041^{\prime \prime}$ \\
\hline Number of family & & & & & & & & & & & & \\
\hline - $(1-3)$ & 123 & 72.8 & 46 & 27.2 & & & 82 & 58.2 & 59 & 41.8 & & \\
\hline - $(4-6)$ & 22 & 71.0 & 9 & 29.0 & 0.043 & .835 & 32 & 54.2 & 27 & 45.8 & 0.261 & .612 \\
\hline
\end{tabular}

Note. ${ }^{*}$ Significant at level $p<.05$

Published by Sciedu Press 
Table 6. Relation between students' socio-demographic characteristics and their academic behavior total score

\begin{tabular}{|c|c|c|c|c|c|c|c|c|c|c|c|c|}
\hline & \multicolumn{12}{|c|}{ Academic behavior } \\
\hline & \multicolumn{6}{|c|}{ First year } & \multicolumn{6}{|c|}{ Fourth year } \\
\hline & \multicolumn{2}{|c|}{ Low } & \multicolumn{2}{|c|}{ High } & \multirow{2}{*}{$\chi^{2}$} & \multirow{2}{*}{$p$-value } & \multicolumn{2}{|c|}{ Low } & \multicolumn{2}{|c|}{ High } & \multirow{2}{*}{$\chi^{2}$} & \multirow{2}{*}{$p$-value } \\
\hline & $\mathbf{N}$ & $\%$ & $\mathbf{N}$ & $\%$ & & & $\mathbf{N}$ & $\%$ & $\mathbf{N}$ & $\%$ & & \\
\hline \multicolumn{13}{|l|}{ Age } \\
\hline - 20 & 177 & 89.4 & 21 & 10.6 & \multirow{2}{*}{0.237} & \multirow{2}{*}{.626} & & & & & & \\
\hline - 20 or more & 2 & 100.0 & 0 & 0.0 & & & & & & & & \\
\hline \multicolumn{13}{|l|}{ Sex } \\
\hline - Male & 60 & 88.2 & 8 & 11.8 & \multirow{2}{*}{0.175} & \multirow{2}{*}{.675} & 47 & 81.0 & 11 & 19.0 & \multirow{2}{*}{3.995} & \multirow{2}{*}{$.046^{*}$} \\
\hline - Female & 119 & 90.2 & 13 & 9.8 & & & 95 & 66.9 & 47 & 33.1 & & \\
\hline \multicolumn{13}{|l|}{ Residence } \\
\hline - Urban & 58 & 90.6 & 6 & 9.4 & \multirow{2}{*}{0.127} & \multirow{2}{*}{.722} & 60 & 72.3 & 23 & 27.7 & \multirow{2}{*}{0.115} & \multirow{2}{*}{.735} \\
\hline - Rural & 121 & 89.0 & 15 & 11.0 & & & 82 & 70.1 & 35 & 29.9 & & \\
\hline \multicolumn{13}{|l|}{ Marital status } \\
\hline - Single & 173 & 89.2 & 21 & 10.8 & \multirow{2}{*}{0.726} & \multirow{2}{*}{.394} & 123 & 75.9 & 39 & 24.1 & 10.04 & \multirow{2}{*}{$.002^{*}$} \\
\hline - Married & 6 & 100.0 & 0 & 0.0 & & & 19 & 50.0 & 19 & 50.0 & 8 & \\
\hline \multicolumn{13}{|c|}{ Student with children } \\
\hline - Yes & 5 & 100.0 & 0 & 0.0 & \multirow{2}{*}{0.602} & & 8 & 53.3 & 7 & 46.7 & & \\
\hline - No & 174 & 89.2 & 21 & 10.8 & & .438 & 134 & 72.4 & 51 & 27.6 & 2.458 & .117 \\
\hline Family income & & & & & & & & & & & & \\
\hline - Enough & 153 & 89.0 & 19 & 11.0 & 020 & 527 & 122 & 73.5 & 44 & 26.5 & م. & 006 \\
\hline - Not enough & 26 & 92.9 & 2 & 7.1 & 0.39 & .532 & 20 & 58.8 & 14 & 41.2 & 2.95 & .086 \\
\hline Number of family & & & & & & & & & & & & \\
\hline - $(1-3)$ & 150 & 88.8 & 19 & 11.2 & $0<4$ & 40 & 100 & 70.9 & 41 & 29.1 & 0001 & 071 \\
\hline - $(4-6)$ & 29 & 93.5 & 2 & 6.5 & 0.04 & .424 & 42 & 71.2 & 17 & 28.8 & 0.001 & 潼. \\
\hline
\end{tabular}

Note. ${ }^{*}$ Significant at level $p<.05$

Regarding family income, there was a statistical significant relation between fourth year students' family income and their self-esteem at $\chi^{2}=4.185$, and $p=.041$, while there was no statistical significant relation between first year students' family income and their self-esteem at $\chi^{2}=0.019$, and $p=.891$.

Table 6 presents the relation between students' sociodemographic characteristics and their academic behavior total score, as there was a statistical significant relation between fourth year students' sex and their academic behavior at $\chi^{2}=3.995$, and $p=.046$, while there was no statistical significant relation between first year students' sex and their academic behavior at $\chi^{2}=0.175$, and $p=.675$. Concerning marital status there was a statistical significant relation between fourth year students' marital status and their academic behavior at $\chi^{2}=10.048$, and $p=.002$, while there was no a statistical significant relation between first year students' marital status and their academic behavior at $\chi^{2}=0.726$, and $p=.394$.

\section{Discussion}

Adolescence is a period of life during which many important body changes take place that are determined by pubertal development. ${ }^{[18,19]}$ Body image is one of the most important psychological factors that affects adolescents' personality and behavior, because the adolescents view their body or- gans as separate parts, and each part plays a role in his/her personality. ${ }^{[20,21]}$

The intense concern of body image would cause unfavorable outcomes such as poor health status, anxiety, depression, low self-esteem, and poor quality of life which eventually lead to body shape dissatisfaction. ${ }^{[22]}$ The study questioned about the correlation between body image satisfaction and the academic behavior and also between self-esteem and the academic behavior and compared this among the first and fourth year students in the Faculty of Nursing Tanta University.

So this study aims to explore the relation between body image Satisfaction, self-esteem and the academic behavior among the first and fourth year students in faculty of nursing.

The present study revealed that there was a significant relationship between the first and fourth year students in the satisfaction of their body image shape as the first year students had a large percent of dissatisfaction with their body image that is larger than fourth year students. This may be due to that the first year students recently enter their college with some fear of body image change and concerns about their physical appearance that is associated with the new stage in their life, and also is returned to that the students have just emerged from the protected environment of their family where they are exposed to more competitive situation. 
Also the fourth year students had high dissatisfaction with their body image and this is returned to the higher concerns of students about their appearance especially they were in the graduation stage that is contain building the romantic relationship and marriage and also preparation for the occupational life that affect them.

The results revealed that there was a significant relationship between the first and fourth year students in their self-esteem as this may be due to the higher percentage of them had low self-esteem resulting from high percent of dissatisfaction of their body image. Also the results revealed that there was a significant relationship between the first and fourth year students in their academic behavior this is return to high level of body image dissatisfaction and low level of self-esteem which affect on their level of academic behavior.

The results illustrated that body image dissatisfaction was significant negatively correlated to self-esteem level as if student's body image dissatisfaction increased occur decreasing in self-esteem, because body image dissatisfaction affect student's self-esteem equally for the first and fourth year students. This may be due to over concerning of students by their body image satisfaction and their self-esteem during their graduation phase. This is in accordance to Abamara Nnaemeka C et al. in 2014, who confirmed that there was a significant relationship between body image and self-esteem. This means that body image is inversely related with selfesteem based on negative correlation. It appears that low self-esteem significantly correlated with distorted body image. ${ }^{[23]}$ Also this is in agreement with Tiwari GK in 2014, who stated a significant negative relation between body image dissatisfaction scores and self-esteem of the male and female. ${ }^{[21]}$ In addition this result is in consistent with Pisitsungkagarn $\mathrm{K}$ et al. in 2013, who found that the findings in their study demonstrated that body image satisfaction was positively associated with self-esteem. ${ }^{[19]}$ This is in contrast to Czeglédi E et al. in 2015, who stated that "Our results corroborated an earlier report that in multivariate model body height dissatisfaction does not predict self-esteem, however we failed to replicate their finding that body weight dissatisfaction predicted lower self-esteem". [24]

A significant negative relation between dissatisfaction with body image and academic behavior was found as if body image dissatisfaction increased the academic behavior becomes low as the student's satisfaction decreased and affect on the their academic behavior in the first and fourth year students equally, this may be returned to student's concerns about their body image satisfaction that is may be low and affect on their academic performance. This is in accordance with Miles JM in 2009, who stated that the results indicate that females with higher grade averages and females interested in full-time employment may be less based on their physical appearance. $^{[22]}$

There was a significant positive relation between student's self-esteem and their academic behavior when self-esteem increased the academic achievement increased and the reverse occurred. This is in agreement with Saadat $M$ et al. in 2012, who found in their study presence of positive correlation between self-esteem and academic performance. ${ }^{[25]}$ Also this result is in accordance with Rosli Y et al. in 2012 who stated that a significant moderate relation between selfesteem and cumulative grade point average of students. ${ }^{[26]}$ In addition Arshad $\mathrm{M}$ et al. in 2015, in this study indicated that a strong positive correlation between self-esteem and academic performance between university students, which also found that the findings are highly significant. ${ }^{[27]}$ Gaspard $\mathrm{MB}^{[28]}$ mentioned that students with high self-esteem scores at the pretest assessment tended to have high grade point during the first semester of college student enrollment.

From the findings of this study there was a significant relation between body image dissatisfaction and the students' gender as the female first and fourth year students had high body image dissatisfaction than the males this may be due to their concerns about their physical appearance, also girls wish to decrease weight to become thinner, while boys wish to gain weight and increase muscle mass. Also, girls who showed low satisfaction with their bodies, as a consequence of the struggle to accept and to provide a mental integration of the life and pubertal changes, and this could be due to the culturally-imposed slimness model, and indicates that overweight is a risk factor for body dissatisfaction, and also had low self-esteem. This is in accordance with Gatti E in 2014, who mentioned that Girls appeared more dissatisfied with their bodies and seemed to be at more risk of engaging in dysfunctional eating behaviors than boys. ${ }^{[18]}$ Also this is in agreement with Gillen MM et al. who mentioned that male students were more satisfied with their body image than female students. ${ }^{[29]}$ In addition, Yahia $\mathrm{N}$ et al. stated that male students were less worried about their body image compared to females. ${ }^{[30]}$ Also Coelho EM in 2016 mentioned that more girls $(50.2 \%)$ than boys $(39.8 \%)$ had a thin body, while more boys wished to be larger $(15.8 \%$ vs. $10.6 \%) .{ }^{[31]}$

There was a significant relationship between dissatisfaction with body image and the students' residence as rural first year students had low body image dissatisfaction than the urban ones. While the rural fourth year students had high body image dissatisfaction than the urban ones, as this is returned to first year students entering a new environment that is may be frightening and affect their identity and behav- 
ior. This is in accordance with Triches et al. in 2007, who found different levels of body dissatisfaction, with greater dissatisfaction among those from urban areas. ${ }^{[32]}$

In contrast with Fidelix YL et al. 2011, who stated that their study was unable to demonstrate an association between area of residence (rural and urban) and body image dissatisfaction. The prevalence of body dissatisfaction was similar among adolescents from rural $(51.3 \%)$ and urban areas $(59.9 \%){ }^{[33]}$

The single fourth year students had low body image dissatisfaction than the married ones as there were a significant relation between body image dissatisfaction and the students' marital status as this may be due to over concern of physical appearance as they had not get marriage yet. This is in accordance with Garousi S et al. in 2012, their results indicated that although body image dissatisfaction exists in both married and single people, married people have shown lesser body dissatisfaction. ${ }^{[34]}$

The results mentioned that there was a significant relation between first year college students' self-esteem and their gender as female had low self-esteem than the males. The probable causes of these findings may be more independent status of males than of females, which is given them by culture. Hence this given status makes males comparatively more social and strong and this may lead to student's concerns about their body image satisfaction that is may be low and affect on their self-esteem and academic behavior. This is in accordance with Arshad $\mathrm{M}$ et al., who indicated that male students have high scores on self-esteem as compared to female students and the results are significant. It was found that females had significantly higher self-esteem scores than male between students. ${ }^{[27]}$ This is in contrary to Naderi H et al. in 2014 , who found that females had significantly higher self-esteem scores than male students. ${ }^{[35]}$

There was a significant relationship between first year student's self-esteem and their residence, as rural students had low self-esteem than urban ones and this is due to students entering a new environment that is may be frightening and affect their identity and behavior. This is in contrast to the study of Saeedinejat S et al. in 2014, who stated that "we did not find any significant association between self-esteem and the place of residence of students". [36]

Regarding student's academic behavior there was a significant relationship between fourth year students' gender and their academic behavior as female students had low academic behavior than males and this result from low body image satisfaction and low self-esteem as this is the very important part of life for female and affect them. This is in contrast to Arshad M in 2015, who stated that female students had higher academic performance than male students. It also supports the results that there is a significant difference between female and male student's scores on academic performance. ${ }^{\text {[27] }}$ Also Wan Chik WZ et al. in 2012, who mentioned that the males were also found to have lower academic performance than female students, as measured by grade point average. ${ }^{[37]}$

There was a significant relationship between fourth year students' marital status and their academic behavior as married students had low academic behavior than single ones and this may be due to the academic behavior becomes low as the student's body image satisfaction and self-esteem decreased and affect on the their academic behavior. This is in contrast to McLaughlin $\mathrm{N}$ in 2015, who showed that there was a significant difference in grade point average between those who indicated "single" and those "in a relationship". The data pointed out that those "in a relationship" reported higher grade point averages. ${ }^{[38]}$

\section{Conclusions}

Students had a large percent of dissatisfaction with their body image and low level of self-esteem; also they had low level of academic behavior. Body image dissatisfaction was significant negatively correlated with self-esteem and there was a significant negative relation between dissatisfaction with body image and academic behavior. Also there was a significant positive correlation between student's self-esteem and their academic behavior.

\section{Recommendations}

- Further studies proposed to assess the proportion of adolescents perceiving their body image as normal and to examine the factors influencing body image perception.

- Develop individual counseling workshops for students who struggling with body image and self-esteem, to improve their coping skills and academic achievement.

- Exercise based interventions have been found to be beneficial in enhancing body image that result in enhancement of self-esteem and academic achievement.

- Improving relations with family and friends and increasing social engagement to enhance self-esteem and body image satisfaction.

- The results of the present study suggest that it is important to educate adolescents about changes they experience during the phase of puberty, and about a realistic $\&$ positive body image.

\section{CONFlicts OF InTEREST Disclosure}

The authors declare they have no conflicts of interest. 


\section{REFERENCES}

[1] Moeen T, Muazzam A, Zubair B. Development and Validation of Body Image Scale (BIS) For Young Adult Females. Pakistan Journal of Social and Clinical Psychology. 2013; 11(1): 52-58.

[2] Mahajan N, Kaur J. Relation Between Locus of Control of College Teachers and Their Job Satisfaction. International Journal of Applied Psychology. 2012; 2(5): 98-103. https://doi.org/10.5923/j. ijap. 20120205.04

[3] Abadseh A. Dissatisfaction with Body Image and Its Relationship with Depression in a Sample of Teenage Palestinian at Gaza Strip. Islamic Journal of Educational and Psychological Studies. 2013; 21(2): 41-61.

[4] Koyunchu M, Tok S, Canpolat AM, et al. Body image satisfaction and dissatisfaction, social physique anxiety, self-esteem, and body fat ratio in female exercisers and non exercisers. Social Behavior personality. 2010; 38(4): 561-70. https://doi.org/10.2224/sb p.2010.38.4.561

[5] Yanover T, Thompson JK. Eating problems, body image disturbances, and academic achievement: Preliminary evaluation of the eating and body image disturbances academic interference scale. International Journal of Eating Disorders. 2008; 41(2): 184-7. PMid: 17922531. https://doi.org/10.1002/eat. 20483

[6] Seligman L. Theories of counseling and psychotherapy: Systems, strategies, and skills. Upper Saddle River: NJ: Pearson Education Inc.; 2006

[7] Clay D, Vignoles VL, Dittmar H. Body image and self-esteem among adolescent girls: Testing the influence of sociocultural factors. Journal of Research on Adolescence. 2005; 15(4): 451-477. https://doi.org/10.1111/j.1532-7795.2005.00107.x

[8] van den Berg PA, Jonathan M, Marla Eisenberg, et al. The link between body dissatisfaction and self-esteem in adolescents: Similarities across gender, age, weight status, race/ethnicity, and socioeconomic status. Journal of Adolescents Health. 2010; 47(3): 290-6. PMid: 20708569. https ://doi .org/10.1016/j.jadohe alth.2010.02.004

[9] Aryana M. Relationship Between Self-esteem and Academic Achievement Amongst Pre-University Students. Journal of Applied Sciences. 2010; 10: 2474-7. https ://doi.org/10.3923/jas. 20 10.2474 .2477

[10] Jowkari B, Kojari J. Academic resilience in education: the role of achievement goal orientations. Journal of Advances in Medical Education and Professionalism. 2014; 2(1): 33-8.

[11] Phagat P. Relationship between Self-esteem and Academic Achievement of Secondary School Students. International Journal of Innovative Research \& Development. 2016; 5(7): 211-6.

[12] Lowery SE, Sharon E, Kurpius R, et al. Body image, self-esteem, and health-related behaviors among male and female first year college students. Journal of College Student Development. 2005; 46: 612-23. https://doi.org/10.1353/csd.2005.0062

[13] Hoogeveen L, Van Hell JG, Verhoeven L. Self-concept and social status of accelerated and nonaccelerated students in the first 2 years of secondary school in the Netherlands. Gifted Child Quarterly Journal. 2009; 53(1): 50-67. https://doi.org/10.1177/001698620832 6556

[14] Raymer KE. The Effects of Social Media Sites on Self-esteem. A Thesis of Masters of Arts in School Psychology at Rowan University. 2015.

[15] Cooper PJ, Taylor MJ, Cooper Z, et al. The development and validation of the body shape questionnaire. International Journal of Eating Disorder. 1987; 6(4): 485-494. https ://doi .org/10.1002/1098 -108X (198707)6:4<485: :AID-EAT2260060405>3.0.CO;2-0
[16] Rosenberg M. Society and the adolescent self-image. Princeton, NJ: Princeton University Press; 1965. https : //doi .org/10.1515/97 81400876136

[17] Gupta C. The Relation between Body Image Satisfaction and Selfesteem to Academic Behaviour in Adolescents and Pre-adolescents, University of Manitoba. 2011.

[18] Gatti E, Ionio C, Traficante D, et al. "I Like My Body; Therefore, I Like Myself": How Body Image Influences Self-Esteem-A CrossSectional Study on Italian Adolescents. Europe's Journal of Psychology. 2014; 10(2): 301-317.

[19] Pisitsungkagarn K, Taephant N, Attasaranya P. Body image satisfaction and self-esteem in Thai female adolescents: the moderating role of self-compassion. Int J Adolesc Med Health. 2013; 1-6.

[20] Qaisy LM. Body Image and Self-esteem Among Israel University Students. British Journal of Education. 2016; 4(8): 63-71.

[21] Tiwari GK. Body Image Satisfaction Enhances Self-Esteem. 2014.

[22] Miles JM. Academic Achievement and Body Image in Undergraduate Women. Higher Education Leadership Program. University of Arkansas. 2009.

[23] Abamara NC, Agu SA. Relationship between Body Image and SelfEsteem among Female Undergraduate Students of Behavioural Sciences. Iosrjournals Org. 2014; 19(1): 01-05.

[24] Czeglédi E, Probst M, Babusa B. Body dissatisfaction, trait anxiety and self-esteem in young men. Psihijat.dan. 2015; 47(1): 29-41.

[25] Saadat M, Ghasemzadeh A, Soleimani M. Self-esteem in Iranian university students and its relationship with academic achievement. Procedia - Social and Behavioral Sciences. 2012; 31(31): 10-14. https://doi.org/10.1016/j.sbspro.2011.12.007

[26] Rosli Y, Othman H, Ishak I, et al. Self-esteem and academic performance relationship amongst the second year undergraduate students of Universiti Kebangsaan Malaysia, Kuala Lumpur Campus. Procedia - Social and Behavioral Sciences. 2012; 60(3): 582-589. https://doi.org/10.1016/j.sbspro.2012.09.426

[27] Arshad M, Muhammad S, Zaidi IH, et al. Self-Esteem \& Academic Performance among University Students. Journal of Education and Practice. 2015; 6(1).

[28] Gaspard MB, Burnett MF, Gaspard CP. The Influence of Self-Esteem and Selected Demographic Characteristics on First Semester Academic Achievement of Students Enrolled in a College of Agriculture. Journal of Agricultural Education. 2011; 52(4): 76-86. https://doi.org/10.5032/jae.2011.04076

[29] Gillen MM, Lefkowitz ES. Gender and Racial/Ethnic Differences in Body Image Development Among College Students. Body Image. 2012 January; 9(1): 126-130. PMid: 21983339. https://doi.or g/10.1016/j.bodyim. 2011.09.004

[30] Yahia N, El-Ghazale H, Achkar A, et al. Dieting practices and body image perception among Lebanese university students. Asia Pac J Clin Nutr. 2011; 20(1): 21-28. PMid: 21393106.

[31] Coelho EM, Fonseca SC, Pinto GS, et al. Factors associated with body image dissatisfaction in Portuguese adolescents: obesity, sports activity and TV watching. Motricidade. 2016; 12(2): 18-26. https : //doi.org/10.6063/motricidade. 6277

[32] Triches RM, Giugliani ERJ. Body dissatisfaction in school children from two cities in the South of Brazil. Rev Nutr. 2007; 20(2): 119-28. https://doi.org/10.1590/S1415-52732007000200001

[33] Fidelix YL, Silva DAS, Pelegrini A, et al. Body image dissatisfaction among adolescents from a small town: Association with gender, age, and area of residence. Rev Bras Cineantropom Desempenho Hum. 2011; 13(3): 202-207.

[34] Garousi S, Garrusi B, Divsalar F, et al. Body Satisfaction and Management in Iranian Students. Mat Soc Med. 2012; 24(1): 34-37. PMid: 23922514. https://doi.org/10.5455/msm.2012.24.34-37 
[35] Naderi H, Abdullah R, Aizan HT, et al. Self Esteem, Gender and Academic Achievement of Undergraduate Students. American Journal of Scientific Research. 2009; 3: 26-37.

[36] Saeedinejat S, Ebrahimpour H, Tabatabaee SS, et al. A Survey on Evaluating the Relation between Self-esteem and Quality of Life in Students of Health School Affiliated to Mashhad University of Medical Sciences. Jundishapur Journal of Health Sciences. 2014; 6(2): 351-356.
[37] Chik WZW, Salamonson Y, Everett B, et al. Gender difference in academic performance of nursing students in a Malaysian university college. International Nursing Review. 2012; 59(3): 387-393. https://doi.org/10.1111/j.1466-7657.2012.00989.x

[38] McLaughlin N. An Analysis of the Effect of Relationship Status on Self-Esteem and Academic Performance. Journal of Undergraduate Research. 2015; 25: 1-22. 